Revista de Derecho

\title{
La Convención Americana sobre Derechos Humanos y el matrimonio de las parejas del mismo sexo en Ecuador: una lectura desde un concepto material de la Constitución
}

The American Convention on Human Rights and the marriage of same-sex couples in Ecuador: a reading from a material concept of the Constitution

\section{Claudia Storini}

Docente Universidad Andina Simón Bolivar, Ecuador

claudia.storini@uasb.edu.ec

ORCID: 0000-0002-5604-8615

\section{Marcelo Guerra Coronel}

Docente Universidad Católica de Cuenca, Ecuador

marcegc25@gmail.com

ORCID: 0000-0001-8526-773X

Nathaly Yépez

Asesora de la Corte Constitucional del Ecuador

nayp24@yahoo.com

ORCID: 0000-0002-6470-3851

DOI: https://doi.org/10.32719/26312484.2019.32.1

Fecha de recepción: 29 de abril de 2019

Fecha de aceptación: 31 de julio de 2019

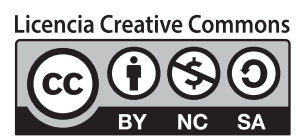




\section{RESUMEN}

En este breve trabajo se busca dotar al lector de elementos jurídicos respecto al concepto material de Constitución, y, a partir de su configuración, analizar el matrimonio entre parejas del mismo sexo en Ecuador. Para ello el texto se ha configurado en tres partes: en una primera se hace referencia a las opiniones consultivas y su valor jurídico en el Sistema Interamericano de Protección de Derechos Humanos; en una segunda se observa el valor de dichas opiniones consultivas en Ecuador a partir de la comprensión del concepto material de su Constitución; y, finalmente en una tercera parte, y a manera de conclusión, se aborda la institución del matrimonio entre parejas del mismo sexo en Ecuador y su completo reconocimiento a partir de un análisis del concepto material de la Constitución ecuatoriana de 2008. En definitiva, se intenta abordar el matrimonio igualitario en Ecuador desde una comprensión clara de los derechos humanos en su dimensión normativa.

Palabras Clave: Constitución, convención, matrimonio, favorabilidad.

\section{ABSTRACT}

In this work, we seek to provide the reader with legal elements regarding the material concept of the Constitution, and from its configuration, analyze equal marriage in Ecuador. The text has been divided into three parts; in the first part, reference is made to advisory opinions and their legal value in the Inter-American System for the Protection of Human Rights; in a second, the value of said advisory opinions in Ecuador is observed from the understanding of the material concept of its Constitution; and finally, the institution of equal marriage in Ecuador and its full recognition based on analysis of the material concept of the Ecuadorian Constitution of 2008. In short, we try to address equal marriage in Ecuador with total legal objectivity, based on academic rigor and a clear understanding of human rights in its normative dimension.

KEYWORDS: Constitution, convention, marriage, favorability.

\section{INTRODUCCIÓN}

i bien las discusiones en torno a la familia y sus posibles formas de fundarla conllevan a discusiones escabrosas, en la vigente Constitución del año 2008 aquellas derivaron en la redacción y aprobación de los artículos 67 y 68 del texto constitucional. ${ }^{1}$

1. Constitución de la República del Ecuador: 
Ahora bien, el debate sobre la ampliación del contenido de los derechos en materia de familia en Ecuador contemplados en aquellos artículos de la Constitución retornó con fuerza a partir de la emisión de la opinión consultiva OC-24/17 de la Corte Interamericana de Derechos Humanos (en adelante opinión consultiva OC-24/17 de la Corte IDH $)^{2}$ y de las diferentes acciones constitucionales emprendidas por parejas de personas del mismo sexo, que buscan acceder a la figura del matrimonio como cualquier pareja heterosexual. ${ }^{3}$

Así, una de las discusiones centrales que se ha planteado y que es materia de conocimiento de la Corte Constitucional, ${ }^{4}$ como máximo organismo de interpretación constitucional $^{5}$ en los casos $010-18-\mathrm{CN}$ y $011-18-\mathrm{CN},{ }^{6}$ es si las parejas del mismo sexo pueden (o no) contraer matrimonio en Ecuador. Entre otros aspectos, consideramos que el nudo central en este tema es la antinomia entre la norma del artículo 67 de la Constitución ecuatoriana, que define a nivel constitucional el matrimonio como la unión entre hombre y mujer, y la norma del artículo 17.2 de la Convención Americana sobre Derechos Humanos (CADH), que fue interpretada por la opinión consultiva

“Art. 67.- Se reconoce la familia en sus diversos tipos. El Estado la protegerá como núcleo fundamental de la sociedad y garantizará condiciones que favorezcan integralmente la consecución de sus fines. Estas se constituirán por vínculos jurídicos o de hecho y se basarán en la igualdad de derechos y oportunidades de sus integrantes.

El matrimonio es la unión entre hombre y mujer, se fundará en el libre consentimiento de las personas contrayentes y en la igualdad de sus derechos, obligaciones y capacidad legal".

“Art. 68.- La unión estable y monogámica entre dos personas libres de vínculo matrimonial que formen un hogar de hecho, por el lapso y bajo las condiciones y circunstancias que señale la ley, generará los mismos derechos y obligaciones que tienen las familias constituidas mediante matrimonio.

La adopción corresponderá solo a parejas de distinto sexo".

2. Corte IDH, Identidad de género, e igualdad y no discriminación a parejas del mismo sexo. Obligaciones estatales en relación con el cambio de nombre, la identidad de género, y los derechos derivados de un vínculo entre parejas del mismo sexo (interpretación y alcance de los artículos 1.1, 3, 7, 11.2, 13, 17, 18 y 24, en relación con el artículo 1 de la Convención Americana sobre Derechos Humanos), Opinión Consultiva OC-24/17 de 24 de noviembre de 2017. Serie A n. ${ }^{\circ} 24$.

3. Por ejemplo, los procesos de acción de protección planteados en Quito-Pichincha n. ${ }^{\circ} 174602018000921$, n. ${ }^{\circ} 17159201800006$, n. $^{\circ} 17230201810289$; los procesos de acción de protección planteados en CuencaAzuay n. ${ }^{\circ} 01204201803635$, n. $^{\circ} 01204201803637$.

4. Corte Constitucional del Ecuador, causa n. ${ }^{\circ}$ 0011-18-CN, juez ponente Ramiro Ávila; esta causa corresponde a la consulta de constitucionalidad de norma elevada a la Corte Constitucional por la Sala Penal

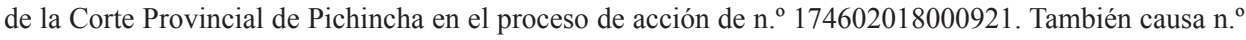
0010-18-CN, juez ponente Alí Lozada; consulta de constitucionalidad de norma elevada a la Corte Constitucional por la Unidad Judicial Civil con sede en la Parroquia Iñaquito con sede en el Distrito Metropolitano de Quito en el proceso de acción de n. ${ }^{\circ} 17230201811800$.

5. Constitución de la República del Ecuador, artículo 436.

6. Cabe mencionar que el artículo fue entregado antes de que la Corte Constitucional se pronunciara con las sentencias 010 18-CN/19 y 011-18-CN/19, y por lo tanto, no se ha incluido el análisis de dichas sentencias, además que los criterios de los autores son diferentes respecto de las sentencias referidas. 
OC-24/17 de la Corte IDH, en la que se establece que los Estados deben garantizar el acceso a todas las figuras ya existentes en los ordenamientos jurídicos internos, incluyendo el derecho al matrimonio, para asegurar la protección de todos los derechos de las familias conformadas por parejas del mismo sexo. ${ }^{7}$

En ese orden de ideas, en el presente artículo presentamos las razones por las cuales el Ecuador se encuentra ineludiblemente obligado a resolver dicha antinomia a favor de las parejas del mismo sexo.

En cierta forma, también se responde a algunas posiciones para desconocer y desmerecer el avance en el reconocimiento de derechos que ha realizado la Corte IDH en su opinión consultiva OC-24/17, así como de los mecanismos constitucionales ecuatorianos que existen para dar paso a este avance.

\section{A "VUELTAS" CON LA OBLIGATORIEDAD DE LAS OPINIONES CONSULTIVAS DE LA CORTE INTERAMERICANA DE DERECHOS HUMANOS}

Uno de los aspectos centrales en los que se ha enfrascado la discusión sobre el reconocimiento del matrimonio para las parejas del mismo sexo y se han dado vueltas en círculos, es si las opiniones consultivas de la Corte IDH -específicamente de la OC-24/17- son o no de obligatorio cumplimiento para Ecuador; y, en consecuencia, si deben o no ser aplicadas directamente. Estos planteamientos, a nuestro entender, no son realmente relevantes a la hora de decidir por una salida constitucional y pueden constituir falsos dilemas si no se comprende cuál es la naturaleza de las opiniones consultivas de la Corte IDH -específicamente de la OC-24/17-, y cómo operan en nuestro sistema constitucional.

\section{Naturaleza de las OPINIONES CONSUltivas}

En primer lugar, se debe ubicar a las opiniones consultivas de la Corte IDH como instrumentos del Sistema Interamericano de Derechos Humanos, del cual el Ecua-

7. Corte IDH, Opinión Consultiva OC-24/17, párrafo 229: "Por las razones expuestas, en interpretación de los artículos 1.1, 2, 11, 17, 18 y 29 de la Convención Americana sobre Derechos Humanos LA CORTE [...] ES DE OPINIÓN por unanimidad, que: 8. De acuerdo a los artículos 1.1, 2, 11.2, 17 y 24 de la Convención es necesario que los Estados garanticen el acceso a todas las figuras ya existentes en los ordenamientos jurídicos internos, incluyendo el derecho al matrimonio, para asegurar la protección de todos los derechos de las familias conformadas por parejas del mismo sexo, sin discriminación con respecto a las que están constituidas por parejas heterosexuales, en los términos establecidos en los párrafos 200 a 228 ”. 
dor forma parte por haber ratificado, tanto la Carta de la Organización de Estados Americanos ${ }^{8}$ como la Convención Americana sobre Derechos Humanos (en adelante CADH), ${ }^{9}$ en la década de 1950 y 1970, respectivamente. Es en la CADH en la que se constituyó la Corte IDH. ${ }^{10}$

Por el principio del pacta sunt servanda ${ }^{11}$ surge entonces la responsabilidad internacional de que el Estado cumpla de buena fe con todos los compromisos internacionales asumidos en estos tratados, incluyendo la obligación de observar las competencias atribuidas a la Corte IDH, contempladas en los artículos 61 al 65 de la CADH. Es decir, el Estado ecuatoriano debe observar las resoluciones de la Corte IDH que emanen de su competencia jurisdiccional contenciosa y consultiva: la primera, en la que resuelve peticiones individuales de vulneración de derechos; $;{ }^{12} \mathrm{y}$, la segunda, por la cual emite las denominadas opiniones consultivas, intrínsecamente relacionadas con la facultad de la Corte de ser último intérprete autorizado de la CADH. ${ }^{13}$

Las opiniones consultivas de la Corte IDH son interpretaciones autorizadas ${ }^{14}$ que realiza la Corte sobre el contenido y alcance de las disposiciones de la CADH y de todo tratado internacional concerniente a derechos humanos de un Estado de las Américas. ${ }^{15}$ Esta interpretación se realiza por petición de la Comisión Interamericana de Derechos Humanos o de uno de los Estados sometidos al sistema, en virtud de su función consultiva contemplada en el art. 64.1 de la CADH.

A diferencia de la facultad contenciosa, por la cual la Corte IDH resuelve situaciones concretas de vulneración de derechos, en las opiniones consultivas la Corte realiza una actividad eminentemente jurídica, ${ }^{16}$ con base en las inquietudes puestas en su conocimiento.

8. CIDH, Carta de la OEA, fecha de ratificación 12/21/50 y fecha de depósito 12/28/50. Ver en 〈https://www. cidh.oas.org/Basicos/Spanish/CartaOEArat.htm>, consulta realizada el 28 de abril de 2019.

9. OEA, CADH, fecha de ratificación el 12/08/77 y fecha de depósito 12/28/77. Ver en 〈https://www.oas.org/dil/ esp/tratados_B32_Convencion_Americana_sobre_Derechos_Humanos_firmas.htm>, consulta realizada el 28 de abril de 2019.

10. $\mathrm{CADH}$, artículos 52 y siguientes.

11. Convención de Viena sobre el Derecho de los Tratados, artículo 26: "Pacta suntservanda". Todo tratado en vigor obliga a las partes y debe ser cumplido por ellas de buena fe".

12. CADH, artículo 61 .

13. Corte IDH, Opinión Consultiva OC-24/17, párr. 16; Opinión Consultiva OC-21/14, párr. 19; Opinión Consultiva OC-22/16, párr. 16. Jurisprudencia de casos contenciosos como la sentencia del Caso Chinchilla Sandoval y otros vs. Guatemala, Excepción Preliminar, Fondo, Reparaciones y Costas. Sentencia de 29 de febrero de 2016, Serie C n. ${ }^{\circ} 312$, párr. 242.

14. Pedro Nikken, La Función Consultiva de la Corte Interamericana de Derechos Humanos, Biblioteca Jurídica Virtual del Instituto de Investigaciones Jurídicas de la UNAM, 〈https://nidh.com.br/wp-content/ uploads/2018/06/5.-Pedro-NIkken-Fun\%C3\%A7\%C3\%A3o-consultiva.pdf», consulta 27 de abril de $2019,176$.

15. Corte IDH, Opinión Consultiva OC-16/99, párr. 47; Opinión Consultiva OC-17/02, párr. 33.

16. Nikken, La Función Consultiva de la Corte Interamericana de Derechos Humanos, 174-5. 
Si bien con respecto a la fuerza vinculante existieron expresiones ambiguas por la propia Corte al analizar su propia competencia, que hacían dudar de la fuerza vinculante de las opiniones consultivas, ${ }^{17}$ en su más reciente jurisprudencia, en especial desde la sentencia en el caso Almonacid Arellano y otros vs. Chile del año 2006, la Corte ha afianzado el valor y la obligatoriedad de las opiniones consultivas para los Estados al enfatizar, por un lado, que en el control de convencionalidad el poder judicial se debe tomar en cuenta todas las interpretaciones realizadas de la $\mathrm{CADH} ;{ }^{18} \mathrm{y}$, por otro, que estos instrumentos vinculan a todos los Estados de las Américas que hayan ratificado la $\mathrm{CADH}$, como es el caso del Estado ecuatoriano, incluso de aquellos Estados que sin haber ratificado aquel tratado son parte del sistema interamericano. ${ }^{19}$

Por lo tanto, no se puede leer ni aplicar la CADH sin tomar en cuenta la interpretación que ha realizado la Corte IDH sobre el contenido de sus disposiciones en sus opiniones consultivas.

\section{Las OPINIONES CONSUltivas Y la CONSTITUCión ECUATORIANa}

Ahora cabe preguntarse cómo operan en nuestro ordenamiento jurídico las opiniones consultivas y en concreto la OC-24/14 de la Corte IDH. La respuesta parte del mismo artículo 11 núm. 3 inc. 1 de la Constitución de la República ${ }^{20}$ y en el art. 426 de la misma

17. Ibíd., 173-4.

18. Corte IDH, Caso Almonacid Arellano y otros vs. Chile. Sentencia de 26 de septiembre de 2006 (Excepciones Preliminares, Fondo, Reparaciones y Costas), párr. 124.

19. IDH, Opinión Consultiva OC-21, párr. 31: “[...] Es por tal razón que estima necesario que los diversos órganos del Estado realicen el correspondiente control de convencionalidad 23, también sobre la base de lo que señale en ejercicio de su competencia no contenciosa o consultiva, la que innegablemente comparte con su competencia contenciosa el propósito del sistema interamericano de derechos humanos, cual es, "la protección de los derechos fundamentales de los seres humanos". 24. A su vez, a partir de la norma convencional interpretada 25 a través de la emisión de una opinión consultiva, todos los órganos de los Estados Miembros de la OEA, incluyendo a los que no son Parte de la Convención pero que se han obligado a respetar los derechos humanos [...] cuentan con una fuente que, [...] contribuye [...] a lograr el eficaz respeto y garantía de los derechos humanos.

20. Ecuador, Constitución de la República:

"Art. 11.- El ejercicio de los derechos se regirá por los siguientes principios:

3. Los derechos y garantías establecidos en la Constitución y en los instrumentos internacionales de derechos humanos serán de directa e inmediata aplicación por y ante cualquier servidora o servidor público, administrativo o judicial, de oficio o a petición de parte.

Para el ejercicio de los derechos y las garantías constitucionales no se exigirán condiciones o requisitos que no estén establecidos en la Constitución o la ley.

Los derechos serán plenamente justiciables. No podrá alegarse falta de norma jurídica para justificar su violación o desconocimiento, para desechar la acción por esos hechos ni para negar su reconocimiento". 
norma ${ }^{21}$. En estas se contemplan los principios de aplicación directa e inmediata de los instrumentos internacionales de derechos humanos por parte de cualquier servidor público, y el de favorabilidad en el caso de tratados internacionales más favorables.

En ese sentido, para dilucidar la antinomia sobre ampliar (o no) el reconocimiento del matrimonio para las parejas del mismo sexo, se debe tomar en cuenta y aplicar la CADH por disposición expresa de nuestra Constitución, ya que en sus artículos 11, 17 y 24 de la CADH se reconoce los derechos humanos a la vida privada, a la protección de familia y a la igualdad, respectivamente; y que han sido interpretados por la opinión consultiva OC-24/17 de la Corte IDH.

En otras palabras, resulta irrelevante que la discusión respecto a la obligatoriedad jurídica de la opinión consultiva OC-24/17 de la Corte IDH y si es o no aplicable directamente, debido a que lo que se debe aplicar directamente no es la opinión consultiva, sino la $\mathrm{CADH}$, que, por disposición de la propia Corte IDH como máximo intérprete de aquella, encuentran desarrollo el contenido de sus normas en la opinión consultiva OC-24/17. El Estado ecuatoriano, en especial los jueces constitucionales, no pueden dejar de aplicar la CADH sin observar lo resuelto por la Corte IDH, cuestión que incluso ya fue tratada por la Corte Constitucional del Ecuador en su sentencia 184-18-SEP-CC, en la que se mencionó la naturaleza de las opiniones consultivas en Ecuador y los efectos jurídicos que esta genera.

\section{LA CONVENCIÓN AMERICANA A SOBRE DERECHOS HUMANOS Y SU VALOR JURÍDICO EN EL ORDENAMIENTO JURÍDICO ECUATORIANO}

El valor jurídico de los instrumentos internacionales de protección de derechos humanos, entendiendo entre estos a los tratados, dentro de los Estados, merece el análisis a partir de tres factores. El primero, atinente a la vinculación soberana del

21. Ecuador, Constitución de la República:

Art. 426.- "Todas las personas, autoridades e instituciones están sujetas a la Constitución.

Las juezas y jueces, autoridades administrativas y servidoras y servidores públicos, aplicarán directamente las normas constitucionales y las previstas en los instrumentos internacionales de derechos humanos siempre que sean más favorables a las establecidas en la Constitución, aunque las partes no las invoquen expresamente.

Los derechos consagrados en la Constitución y los instrumentos internacionales de derechos humanos serán de inmediato cumplimiento y aplicación. No podrá alegarse falta de ley o desconocimiento de las normas para justificar la vulneración de los derechos y garantías establecidos en la Constitución, para desechar la acción interpuesta en su defensa, ni para negar el reconocimiento de tales derechos. 
Estado con alguno de esos instrumentos, ya directa o indirectamente ${ }^{22}$; el segundo, el valor que los Estados dan a dichos instrumentos dentro de su ordenamiento jurídico; y, finalmente como tercer factor, aquel referente al sistema de garantías jurisdiccionales de dichos instrumentos al interior de los Estados.

La Corte IDH, organismo internacional jurisdiccional creado en la CADH como máximo intérprete de la convención, ha ido construyendo una institución de suma importancia en el marco del Sistema Interamericano de Derechos Humanos, el llamado Control de Convencionalidad. Un control no expresamente previsto por la $\mathrm{CADH}$, sino resultado del desarrollo de algunos de sus preceptos por parte de la Corte IDH, que, en ejercicio de su facultad interpretativa en numerosas sentencias y opiniones consultivas, ha establecido que el mismo tiene que ser realizado de oficio, ${ }^{23}$ por todas las autoridades estatales ${ }^{24}$ entre las que se encuentran jueces; y, además, no pueden aplicar disposiciones que sean contrarias a las contenidas en la CADH así como a la interpretación que de dichas disposiciones la Corte IDH ha venido realizando en su jurisprudencia y opiniones consultivas sobre este tratado..$^{25}$

La norma fundamental del Ecuador de 2008 ha reconocido a los instrumentos internacionales de derechos humanos valor y fuerza de constitución, pues esto se desprende claramente de la lectura de sus artículos 11 número 3, 426, y 428. En dichos artículos no solo se otorga a estos instrumentos internacionales el mismo valor de la Constitución sino que, además, se constitucionaliza el principio de favorabilidad, por el cual los tratados en materia de derechos humanos pueden llegar incluso a gozar de aplicación preferente respeto del texto constitucional cuando establezcan derechos más favorables, ${ }^{26}$ esto es, que si los artículos de la CADH o sus interpretaciones contienen derechos más favorables a los establecidos en la Constitución, tienen prevalencia en el ordenamiento jurídico interno.

22. Se hace referencia a "vinculación soberana del Estado con algún instrumento de forma directa o indirecta", ya que no en todos los instrumentos existe una vinculación directa, como sucede por ejemplo con los tratados, pues hay otros instrumentos, que ha pesar de no ser un tratado en sentido estricto, los Estados se vinculan a estos, como por ejemplo aquellos instrumentos que desarrollan el tratado o lo interpretan, entonces en función de ello podría decirse que hay una vinculación indirecta, entonces esta división se la realiza solo con fines didácticos, ya que aquellos instrumentos que interpretan el tratado, dependiendo su naturaleza, podrían ser entendidos como parte misma del tratado, como por ejemplo las sentencias y opiniones consultivas que emite la Corte IDH respecto de la CADH.

23. Corte IDH, Caso Trabajadores Cesados del Congreso (Aguado Alfaro y otros) vs. Perú. Excepciones Preliminares, Fondo, Reparaciones y Costas. Sentencia de 24 de noviembre de 2006, párr. 128.

24. Corte IDH, Caso Gelman vs. Uruguay. Fondo y Reparaciones. Sentencia de 24 de febrero de 2011, párr. 239.

25. Corte IDH, Caso Almonacid Arellano vs. Chile. Excepciones Preliminares, Fondo, Reparaciones y Costas, párr. 124.

26. Ecuador, Asamblea Nacional Constituyente, Constitución de la República, en Registro Oficial n. ${ }^{\circ} 449$ (Quito, 20 de octubre, 2008), artículo 424, inciso segundo. 
En este punto se podría afirmar entonces que en Ecuador ya ni siquiera cabría hablar de un control de convencionalidad, pues los instrumentos internacionales de derechos humanos se encuentran constitucionalizados, son constitución, por lo que, en lugar de referir a dicho control o al bloque de constitucionalidad, de lo que cabe hablar aquí es de un concepto ampliado de Constitución, es decir, de una Constitución material. En otras palabras, todo lo concebido como parámetro de convencionalidad -esto es, la $\mathrm{CADH}$, las interpretaciones de la $\mathrm{CADH}$ mediante sentencias y opiniones consultivas de la Corte IDH, y otros tratados de derechos humanos ratificados por el Ecuador e instrumentos de derechos humanos que desarrollen dichos tratados- en Ecuador son parte del concepto material de Constitución, en definitiva, son Constitución.

Entonces, cuando en Ecuador se hace referencia a la garantía de la Constitución, implícitamente también se alude a la garantía de dichos instrumentos internacionales de protección de derechos; por ejemplo, cuando se habla de la garantía control de constitucionalidad, se entiende incorporada a aquella la de control de convencionalidad, es decir, que cuando se hace un control de constitucionalidad en Ecuador, se está cumpliendo, implícitamente, con la obligación internacional de hacer un control de convencionalidad. Para el ordenamiento jurídico del Ecuador la finalidad esencial es garantizar la Constitución en sentido material, y una de las vías para tal fin es hacer un control de constitucionalidad que, a su vez, implica también la realización de un control de convencionalidad y el cumplimiento de la obligación internacional de realizarlo.

Una vez aclarado el valor que el ordenamiento jurídico les da a estos instrumentos como parte integral de la Constitución en sentido material, se podría, por ejemplo, plantear acciones de inconstitucionalidad ante la Corte Constitucional, de ciertas disposiciones infra-constitucionales, por contravenir uno o varios artículos de la CADH y sus interpretaciones, y otros tratados de derechos humanos ratificados por el Ecuador, así como los instrumentos de derechos humanos que desarrollen dichos tratados e inclusive se podrían plantear garantías jurisdiccionales por las acciones u omisiones del Estado o de particulares, que vulneren los derechos contenidos en dichos instrumentos.

De lo antes dicho se podría decir, entonces, que en Ecuador la $\mathrm{CADH}$, las interpretaciones de la $\mathrm{CADH}$ establecidas en las sentencias y opiniones consultivas de la Corte IDH, y otros tratados de derechos humanos ratificados por el Ecuador, poseen garantías normativas y garantías institucionales, o abstractas, que están dirigidas a los poderes públicos, $\mathrm{y}$, además, en caso de vulneración a derechos contenidos en estos instrumentos, se asegura su eventual reparación integral mediante las garantías juris- 
diccionales o reactivas dirigidas a los ciudadanos, ${ }^{27}$ lo cual significa que en Ecuador se encuentra asegurada normativa y jurisdiccionalmente la aplicación directa CADH y sus interpretaciones. En definitiva, todo el sistema de garantías constitucionales creados en la Constitución de 2008 y los que ha desarrollado la Corte Constitucional en su jurisprudencia son también garantías de estos instrumentos de protección de derechos humanos.

Ahora bien, en Ecuador, podríamos decir que existe un control mixto de constitucionalidad, pero no bien configurado, desde la propia Constitución y la Ley Orgánica de Garantías Jurisdiccionales y Control Constitucional, pues, por un lado, existe una facultad difusa ${ }^{28}$ para hacer control constitucional por parte de todos los jueces, y, por otro, un control concentrado por parte de la Corte Constitucional, sin que de la lectura de dichos textos se desprenda un mecanismo para armonizar aquello. Dicha ambigüedad en el sistema de control ha sido contraria a la tradición ecuatoriana y de la mayoría de los países latinoamericanos que establecen controles mixtos de constitucionalidad. De hecho, la misma Constitución ecuatoriana de 1998, siguiendo esa tradición, poseía un sistema de control constitucional mixto, que además de prever un control directo de constitucionalidad, posibilitaba a cualquier juez, y dentro de cualquier proceso, resolver la causa, in-aplicando la disposición que consideraba contraria a la Constitución con efecto inter partes, pero remitiendo un informe sobre dicha actuación al Tribunal Constitucional -denominación que tenía el órgano constitucional en aquel entonces- para que este pudiera resolver, en su caso, sobre la constitucionalidad de la disposición y con efectos erga omnes. ${ }^{29}$

Pese a que de la lectura de la Constitución ecuatoriana de 2008 se descifraba la existencia de un control difuso de constitucionalidad, en el marco de un control mixto, la Corte Constitucional del Ecuador ha emitido sentencias que han eliminado la posibilidad de dicho control, legitimando únicamente la existencia de un control concentrado de constitucionalidad. Específicamente en las sentencias 055-10-SEP-CC, ${ }^{30}$

27. Claudia Storini, "Las garantías constitucionales de los derechos fundamentales en la Constitución ecuatoriana de 2008", en La nueva Constitución del Ecuador, ed. por Santiago Andrade, Agustín Grijalva y Claudia Storini (Quito: Universidad Andina Simón Bolívar, Sede Ecuador / Corporación Editora Nacional, 2009), 289.

28. En este caso se hace referencia a un control difuso de constitucionalidad, entendido como elemento necesario dentro de un control mixto de constitucionalidad, esto es, que todos los jueces puedan hacer ese control inaplicando disposiciones contrarias a la Constitución con un efecto interpartes, mas no se refiere a un modelo puro de control difuso de constitucionalidad como es el originado en Inglaterra con el caso Bonham y en Estados Unidos con el caso Marbury vs. Madison en donde no existen Cortes Constitucionales.

29. Ecuador, Constitución Política de la República del Ecuador, 1998, art. 274.

30. Ecuador, Corte Constitucional, Sentencia $n .^{\circ}$ 55-10-SEP-CC. 
001-13-SCN-CC, ${ }^{31}$ y 030-13-SCN-CC, ${ }^{32}$ ha prohibido a los jueces in-aplicar disposiciones infraconstitucionales que se consideren contrarias a la Constitución, dejando tan solo la posibilidad de realizar una consulta de constitucionalidad ante la misma Corte.

Sin embargo, la decisión de la Corte Constitucional de concentrar el control de constitucionalidad podría generar problemas con el control de convencionalidad y esto en función del concepto material antes referido, pues estarían prohibiendo un control de convencionalidad con características difusas que, como se mencionó antes, es una obligación internacional por parte de todas las autoridades del Estado. En este sentido habría que establecer si, y en qué medida, la consulta de norma, esto es, la cuestión incidental de constitucionalidad, podría suplir el control de convencionalidad con carácter difuso y sustituirlo por un control de convencionalidad concentrado (obviamente, por razones de espacio, estas cuestiones no pueden ser desarrolladas en este trabajo).

Volviendo al problema central de este escrito, queda claro que la CADH y las interpretaciones que realiza la Corte IDH mediante sus sentencias y opiniones consultivas de este tratado son parte del concepto mismo de Constitución en Ecuador, puesto que el constituyente así lo ha establecido, y por ende su eficacia normativa debería estar garantizada, pero que, por un trasplante acrítico del sistema de control, sumado a la interpretación que del mismo ha realizado la Corte Constitucional, dicha eficacia se ha desvanecido, razón por la que se espera que el máximo interprete de la Constitución pueda corregir dichos problemas, $\mathrm{y}$, con ello, garantizar la plena eficacia normativa de la Constitución material en Ecuador.

\section{EL ARTÍCULO 17 CADH A LA LUZ DE LA OPINIÓN CONSULTIVA OC-24/17}

El derecho a la protección a la familia se encuentra reconocido como derecho humano tanto a nivel nacional como internacional. En el caso interamericano, este derecho se consagró en el artículo 17 de la $\mathrm{CADH} .{ }^{33} \mathrm{La}$ primera inquietud que salta a la vista es qué se entiende por familia en la $\mathrm{CADH}$.

31. Ecuador, Corte Constitucional, Sentencia $n .^{\circ}$ 001-13-SCN-CC.

32. Ecuador, Corte Constitucional, Sentencia n $.^{\circ} 030-13-S C N-C C$.

33. Artículo 17 de la CADH.

Protección a la Familia

1. La familia es el elemento natural y fundamental de la sociedad y debe ser protegida por la sociedad y el Estado. 
$\mathrm{Al}$ respecto, la Corte IDH en su reiterada jurisprudencia, desde el año $2002^{34}$, ha sido enfática en señalar que bajo este derecho no se protege un modelo único de familia, ${ }^{35}$ conocida como la familia "tradicional" 36 -entendida como aquella fundada en el matrimonio por una pareja con sus hijos ${ }^{37}$, , sino que abarca un concepto amplio de familia. En la opinión consultiva OC-24/17 la Corte insiste en la interpretación amplia sobre los artículos 11 y 17 de la $\mathrm{CADH}^{38}$ y clarifica que no existe una definición taxativa de familia. ${ }^{39}$

Además, la Corte reconoce la familia como una institución que cambia y evoluciona con el avanzar del tiempo y las sociedades y que "en ocasiones, la evolución de estas nociones ha ocurrido mucho antes que la legislación de un Estado se adapte a las mismas". ${ }^{40}$ En ese sentido, el inciso primero del artículo 67 de la Constitución ecuatoriana coincide con esta visión amplia de familia, ya que reconoce la existencia de la familia en sus diversos tipos y que estas se pueden constituir por vínculos jurídicos o de hecho y que se basarán en la igualdad de derechos y oportunidades. ${ }^{41}$

Así, la Corte IDH, aplicando el método de interpretación evolutiva, arriba, entre otras, a las siguientes conclusiones que son indispensables para comprender la posibilidad de matrimonio para parejas del mismo sexo:

2. Se reconoce el derecho del hombre y la mujer a contraer matrimonio y a fundar una familia si tienen la edad y las condiciones requeridas para ello por las leyes internas, en la medida en que estas no afecten al principio de no discriminación establecido en esta Convención.

3. El matrimonio no puede celebrarse sin el libre y pleno consentimiento de los contrayentes.

4. Los Estados Partes deben tomar medidas apropiadas para asegurar la igualdad de derechos y la adecuada equivalencia de responsabilidades de los cónyuges en cuanto al matrimonio, durante el matrimonio y en caso de disolución del mismo. En caso de disolución, se adoptarán disposiciones que aseguren la protección necesaria de los hijos, sobre la base única del interés y conveniencia de ellos.

5. La ley debe reconocer iguales derechos tanto a los hijos nacidos fuera de matrimonio como a los nacidos dentro del mismo".

34. Corte IDH, Condición jurídica y derechos humanos del niño. Opinión Consultiva OC-17/02 de 28 de agosto de 2002. Serie A n. ${ }^{\circ} 17$.

35. Corte IDH, Opinión Consultiva OC-17/02, párr. 69 y 70.

36. Corte IDH, Atala Riffo y Niñas vs. Chile. Fondo, Reparaciones y Costas. Sentencia de 24 de febrero de 2012, párr. 142; Caso Fornerón e hija vs. Argentina. Fondo, Reparaciones y Costas. Sentencia de 27 de abril de 2012, párr. 98.

37. Corte IDH, Opinión Consultiva OC-24/17, párr. 178.

38. CADH, Artículo 11. Protección de la Honra y de la Dignidad. 2. Nadie puede ser objeto de injerencias arbitrarias o abusivas en su vida privada, en la de su familia, en su domicilio o en su correspondencia, ni de ataques ilegales a su honra o reputación. Artículo 17. Protección a la Familia. 1. La familia es el elemento natural y fundamental de la sociedad y debe ser protegida por la sociedad y el Estado.

39. Corte IDH, Opinión Consultiva OC-24/17 del 24 de noviembre de 2017, párr. 174.

40. Ibíd., párr. 177.

41. Constitución, artículo 67, inciso primero. 
a) no se encuentran motivos para desconocer el vínculo familiar que parejas del mismo sexo pueden establecer por medio de relaciones afectivas;

b) es obligación de los Estados reconocer estos vínculos familiares y protegerlos de acuerdo a la Convención;

c) sería una distinción artificial afirmar que una pareja del mismo sexo no puede gozar de un vínculo familiar como lo podría hacer una pareja heterosexual;

d) este reconocimiento no implica desmerecer otros vínculos familiares;

e) este reconocimiento no implica apartarse de la intención inicial de los Estados que pactaron la Convención; por el contrario, dice la Corte que "reconocer este vínculo familiar el Tribunal se apega a dicha intención original" ya que "la Convención le confiere a los Estados y a la Corte la tarea de descubrir y proteger dichos alcances conforme al cambio de los tiempos";

f) la protección del vínculo familiar de una pareja de personas del mismo sexo trasciende las cuestiones patrimoniales y se extiende a los derechos y obligaciones establecidos por las legislaciones nacionales que surgen de los vínculos familiares de parejas heterosexuales. ${ }^{42}$

Por todas estas premisas, la Corte concluye que la CADH protege el vínculo familiar que puede derivar de una relación de una pareja del mismo sexo sin discriminación alguna con respecto a las parejas de personas heterosexuales.

Con respecto al matrimonio, cuya formulación del inciso segundo del artículo 67 de la Constitución ecuatoriana coincide el artículo 17 número 2 de la $\mathrm{CADH}$, pues ambas definen que el matrimonio es la unión entre un hombre y una mujer, la Corte desarrolla y amplía su contenido.

Para empezar, la Corte señala que, "si bien es cierto que este de manera literal reconoce el 'derecho del hombre y la mujer a contraer matrimonio y fundar una familia', esa formulación no estaría planteando una definición restrictiva de cómo debe entenderse el matrimonio o cómo debe fundarse una familia". ${ }^{43}$

Además, la Corte señala categóricamente que establecer un trato diferente entre las parejas heterosexuales y aquellas del mismo sexo en la forma de fundar una familia "-sea por una unión marital de hecho o un matrimonio civil- no logra superar un test estricto de igualdad", ${ }^{44}$ ya que "no existe una finalidad que sea convencionalmente aceptable". ${ }^{45}$ Por esta razón, la Corte insiste en que argumentos como la procreación,

42. Ibíd., párr. 188-99.

43. Corte IDH, Opinión Consultiva OC-24/17, párr. 189.

44. Ibíd., párr. 220.

45. Ibíd. 
el supuesto significado inamovible de la palabra matrimonio, las convicciones religiosas o filosóficas, no son parámetros validos de convencionalidad. ${ }^{46}$

A pesar de que se reconoce que pueden existir obstáculos en la adecuación normativa para reconocer inmediatamente el derecho de matrimonio a las parejas del mismo sexo, la Corte también deja claro que esta situación no puede ser vista como una autorización para denegar este derecho, "siempre se trata de una situación transitoria". ${ }^{47}$ Por lo tanto, la Corte concluye que: los Estados deben garantizar el acceso a todas las figuras ya existentes en los ordenamientos jurídicos internos, para asegurar la protección de todos los derechos de las familias conformadas por parejas del mismo sexo, sin discriminación con respecto a las que están constituidas por parejas heterosexuales. ${ }^{48}$

\section{ARTÍCULO 67 DE LA CONSTITUCIÓN DEL ECUADOR VS. ARTÍCULO 17.2 CADH}

\section{RAZONES POR LAS QUE NO SE REQUIERE REFORMAR \\ LA CONSTITUCión PARA RECONOCER EL MATRIMONIO ENTRE PAREJAS DEL MisMo SEXo EN ECUAdOR}

$\mathrm{Si}$, como se ha demostrado con anterioridad, el artículo 17.2, así como es interpretado por la OC-24/17, es directamente aplicable y tiene valor y fuerza de constitución, se configuraría en el ordenamiento jurídico ecuatoriano una antinomia interna o en abstracto entre el contenido del citado artículo y el del artículo $67 \mathrm{CE}$.

La antinomia "es aquella situación en la que se encuentran dos normas, cuando una de ellas obliga y la otra prohíbe, o cuando una obliga y la otra permite, o cuando una prohíbe y la otra permite un mismo comportamiento". ${ }^{49}$

Es un choque de dos proposiciones incompatibles, que no pueden ser verdaderas a un mismo tiempo y con relación a un mismo sistema normativo, colisión de dos normas que no pueden ser aplicadas a un mismo tiempo. Más precisamente, una antinomia es interna o en abstracto cuando los supuestos de hecho descritos por las dos normas se superponen conceptualmente. Por ejemplo, una norma que prohíbe el matrimonio entre parejas del mismo sexo y otra que permite dicho matrimonio se hallan en una posición de conflicto abstracto, pues la especie matrimonio entre pareja del

\footnotetext{
46. Ibíd., párr. 221-3.

47. Ibíd., párr. 226-7.

48. Ibíd., párr. 228.

49. Norberto Bobbio, Teoría generale del diritto (Torino: Giappichelli Editore, 2009), 178.
} 
mismo sexo forma parte del género matrimonio; en consecuencia, una de las normas es material o formalmente inválida. ${ }^{50}$ En este sentido, puede constarse la antinomia en abstracto y adelantar su solución sin necesidad de hallarnos en presencia de un caso concreto.

La antinomia es por tanto aquella situación de incompatibilidad, por la cual dos disposiciones normativas se excluyen mutuamente al reclamar cada una de manera exclusiva el mismo ámbito objeto de regulación; será por tanto imposible aplicar a la vez ambas normas, dada la incompatibilidad existente entre las consecuencias jurídicas de las mismas y, sobre todo, por la incoherencia entre los operadores deónticos empleados en ellas. ${ }^{51}$

La configuración de una antinomia se completa, según Bobbio, con dos condiciones: la primera es la pertenencia de las normas al mismo ordenamiento jurídico, o bien a dos ordenamientos no independientes; y la segunda es la identidad en el ámbito de validez de las normas, esto es, material, personal, temporal y espacial. ${ }^{52}$

En el caso en cuestión, como ya se explicó, el artículo 17.2 de la Convención goza de la misma jerarquía que el 67 de la Constitución.

La Constitución y los tratados internacionales de derechos humanos se encuentran en un mismo nivel jerárquico; quedan por tanto ipso facto incorporados al ordenamiento jurídico a nivel constitucional. Sin embargo, desde el punto de vista material, el inciso segundo del artículo 424 de la Constitución establece que: "los tratados internacionales de derechos humanos ratificados por el Estado que reconozcan derechos más favorables a los contenidos en la Constitución, prevalecerán sobre cualquier otra norma jurídica o acto del poder público". Ello significa que la Constitución puede ceder ante un tratado internacional que en el caso concreto otorgue mayor protección a los derechos de la persona. En este sentido, desde su posición privilegiada, los derechos humanos garantizados a nivel internacional determinan la validez de los actos del Constituyente y de las demás fuentes formales de producción normativa. Esto implica que aun reconociendo que la Constitución sigue siendo la norma suprema del ordenamiento jurídico, esta afirmación solo tendrá valor en un sentido estrictamente formal o estructural. Esta afirmación puede explicarse utilizando los conceptos y la diferencia existente entre validez formal y material.

50. José Manuel Cabra Apalategui, “¿Antinomias constitucionales? Una concepción coherentista de las normas de derecho fundamental”, en Abril Uscanga Barradas y Jesús Aquilino Fernández Suárez, Derechos y obligaciones en el Estado de derecho: actas del III Coloquio Binacional México-España, 257-71. Oviedo: Universidad de Oviedo-UNAM, 1978, 259.

51. Victoria Iturralde Sesma, "Una aproximación al tema de las antinomias normativas: problemas relativos a la identificación de las mismas", Anuario de filosofía de derecho, n. 4 (1987): 332.

52. Norberto Bobbio, Teoria dell'ordinamento giuridico (Torino: Giappichelli Editore, 1960), 88-90. 
La validez formal de una disposición depende del cumplimiento de las condiciones formales o procedimentales de su producción, mientras que la validez material se determina exclusivamente en razón de su contenido. ${ }^{53}$

En este caso el artículo 67 de la Constitución del Ecuador podrá ser válido formalmente, aunque no materialmente, ya que su contenido es más restrictivo de los derechos garantizados en el artículo 17.2 de la Convención y, por tanto, axiológicamente contrapuesto a este último.

En este sentido, la validez material debe entenderse como una propiedad que depende del contenido de la norma y este contenido para ser válido deberá ser coherente con los derechos garantizados en el artículo 17.2 de la Convención. La supremacía de la Constitución en relación con su validez material está condicionada al cumplimiento de dos requisitos. El primero es que los actos del constituyente se encuentran siempre controlados por los derechos humanos que, al igual que la Constitución, son axiológicamente supremos. Y, el segundo, se refiere a que una norma constitucional puede ceder en su aplicación frente a una norma internacional sobre derechos humanos si esta ofrece una mayor protección del derecho en cuestión, según el principio establecido por la misma Constitución en el artículo 424.

Lo anterior significa que, en caso de un conflicto entre dos normas (una constitucional y otra internacional) sobre derechos humanos, cuál debe prevalecer en definitiva es un asunto que dependerá de la ponderación de las razones subyacentes a la luz principio de favorabilidad.

53. Guastini distingue entre validez formal y material: la validez formal de una disposición depende de la validez del acto normativo del cual ha sido producida; mientras que la validez material de una disposición depende de la validez de las normas que de la misma pueden obtenerse mediante interpretación. Se dice que una disposición es válida, desde el punto de vista formal, cuando ha sido producida mediante un acto normativo formalmente válido. En otros términos, las condiciones de validez formal de una disposición se resuelven en las condiciones de validez del acto normativo por medio del cual dicha disposición ha sido producida (conformidad a las metanormas sobre la producción jurídica, concretamente las de competencia y de procedimiento, no de la disposición misma, sino del acto normativo). Una disposición normativa es válida desde el punto de vista material cuando las normas (explícitas) que de la misma pueden obtenerse son materialmente válidas. La relación entre los criterios de validez formal y material es la siguiente. La validez formal es una condición ni suficiente ni necesaria de la validez material. De un lado, la validez formal no es condición suficiente de la validez de una norma. En otros términos, una norma explícita puede ser válida desde el punto de vista formal e inválida desde el punto de vista material. Entre los dos criterios de validez se da la siguiente relación: en caso de conflicto entre ellos el criterio material prevalece sobre el formal. En otros términos: si una norma (explicita) es válida desde el punto de vista formal, pero, al mismo tiempo, inválida desde el punto de vista material, es considerada tout court inválida. La validez formal es una validez "débil" mientras la validez material es "fuerte". Riccardo Guastini, "Concetti e criteri di validità", Rivista Trimestrale di Diritto e Procedura Civile, n. ${ }^{\circ} 4$ (1989): 877. 
En este sentido no cabe duda de que el artículo 67 de la Constitución resultaría materialmente inválido y en su lugar debería darse directa aplicación al artículo 17.2 de la CADH.

Las conclusiones indicadas implican que en este caso no sería necesaria una interpretación extensiva o aditiva del articulo 67, provocando una indeseable mutación constitucional para reconocer en Ecuador el matrimonio igualitario ya que, en función de la aplicación directa del artículo 17.2 de la CADH, el artículo 18 del Código Civil y el 52 de Ley Orgánica de Gestión de Identidad y Datos Civiles que establecen que el matrimonio es la unión entre personas de diferente sexo, serían manifiestamente inconstitucionales.

En función del principio de conservación del derecho, y con el objetivo de no generar anomías jurídicas, no debería declararse su inconstitucionalidad ya que bastaría que la Corte Constitucional, bajo el principio de complementariedad, realice una modulación aditiva de dichas disposiciones, esto es, adicionando o incluyendo en el texto de las disposiciones el grupo que ha sido excluido de manera discriminatoria, esto es, las parejas del mismo sexo.

La aplicación directa del artículo 17.2, así como interpretado por la opinión consultiva OC-24/17 de la Corte IDH y la obligación de los Estados de adaptar su ordenamiento a lo establecido en la $\mathrm{CADH}$, así como la imposibilidad de someter este asunto a consulta popular, aconsejaría a que la Corte Constitucional exhortara a la Asamblea Nacional a tomar la iniciativa de una enmienda constitucional del artículo 67.

Dicha reforma, además de eliminar un artículo materialmente inconstitucional, podría tener un fuerte contenido simbólico y por ello ser considerada como parte de una reparación integral tanto para las parejas que aún hoy siguen luchando por sus derechos como para un colectivo históricamente discriminado como el de las personas LGTBIQ.

\section{BIBLIOGRAFÍA}

Alarcón, Pablo. Una metodología comparativa crítica aplicada al sistema constitucional ecuatoriano. Quito: Universidad Andina Simón Bolívar, Sede Ecuador / CEP, 2018.

Bobbio, Norberto. Teoria dell'ordinamento giuridico. Torino: Giappichelli Editore, 1960.

—. Teoría generale del diritto. Torino: Giappichelli Editore, 2009.

Cabra Apalategui, José Manuel. "¿Antinomias constitucionales? Una concepción coherentista de las normas de derecho fundamental". En Abril Uscanga Barradas y Jesús Aquilino Fernández Suárez, Derechos y obligaciones en el estado de derecho: actas del III Coloquio Binacional México-España, 257-71. Oviedo: Universidad de Oviedo-UNAM, 1978. 
Guastini, Riccardo. "Concetti e criteri di validità". Rivista Trimestrale di Diritto e Procedura Civile, n. ${ }^{\circ} 4$ (1989).

Guerra, Marcelo. "El control de convencionalidad. Una mirada a partir de los estándares de la Corte IDH y sus problemas de aplicación en Ecuador". CÁLAMO, Revista de Estudios Jurídicos, n. ${ }^{\circ}$ 5. Quito: Universidad de las Américas, 2016.

Iturralde Sesma, Victoria. "Una aproximación al tema de las antinomias normativas: problemas relativos a la identificación de las mismas". Anuario de filosofía del derecho, n. ${ }^{\circ} 4$ (1987): 331-54.

Nikken, Pedro. "La Función Consultiva de la Corte Interamericana de Derechos Humanos". Biblioteca Jurídica Virtual del Instituto de Investigaciones Jurídicas de la UNAM. 〈https:// nidh.com.br/wp-content/uploads/2018/06/5.-pedro-nikken-fun $\%$ c3\%a $7 \%$ c3\%a3o-consultiva.pdf>. Consulta 27 de abril de 2019.

Storini, Claudia. "Las garantías constitucionales de los derechos fundamentales en la Constitución ecuatoriana de 2008". En La Nueva Constitución del Ecuador, editado por Santiago Andrade, Agustín Grijalva y Claudia Storini. Quito: Universidad Andina Simón Bolívar, Sede Ecuador / Corporación Editora Nacional, 2009.

\section{Normas}

Constitución de la República del Ecuador. Registro Oficial 449, 20 de octubre de 2008.

Convención Americana sobre Derechos Humanos. San José, Costa Rica, 7 al 22 de noviembre de 1969. Entró en vigor el 18 de julio de 1978.

\section{JURISPRUDENCIA}

Ecuador, Corte Constitucional. Sentencia $n$ $^{\circ}$ 55-10-SEP-CC.

-. Sentencia $n .{ }^{\circ} 001-13-S C N-C C$.

- Sentencia $n .{ }^{\circ} 030-13-S C N-C C$.

Corte Interamericana de Derechos Humanos. Caso Gelman vs. Uruguay. Fondo y Reparaciones. Sentencia de 24 de febrero de 2011.

-. Caso Trabajadores Cesados del Congreso (Aguado Alfaro y otros) vs. Perú. Excepciones Preliminares, Fondo, Reparaciones y Costas. Sentencia de 24 de noviembre de 2006.

-. Caso Almonacid Arellano vs. Chile. Excepciones Preliminares, Fondo, Reparaciones y Costas. Sentencia de 26 de septiembre de 2006.

-. Caso Chinchilla Sandoval y otros vs. Guatemala, Excepción Preliminar, Fondo, Reparaciones y Costas. Sentencia de 29 de febrero de 2016.

-. Caso Atala Riffo y Niñas vs. Chile. Fondo, Reparaciones y Costas. Sentencia de 24 de febrero de 2012. 
- Caso Fornerón e hija vs. Argentina. Fondo, Reparaciones y Costas. Sentencia de 27 de abril de 2012.

- El derecho a la información sobre la asistencia consular en el marco de las garantías del debido proceso legal. Opinión Consultiva OC-16/99 de 1 de octubre de 1999.

—. Condición jurídica y derechos humanos del niño. Opinión Consultiva OC-17/02 de 28 de agosto de 2002 .

- Identidad de género, e igualdad y no discriminación a parejas del mismo sexo. Obligaciones estatales en relación con el cambio de nombre, la identidad de género, y los derechos derivados de un vínculo entre parejas del mismo sexo (interpretación y alcance de los artículos 1.1, 3, 7, 11.2, 13, 17, 18 y 24, en relación con el artículo 1 de la Convención Americana sobre Derechos Humanos). Opinión Consultiva OC-24/17 de 24 de noviembre de 2017.

- Derechos y garantías de niñas y niños en el contexto de la migración y/o en necesidad de protección internacional. Opinión Consultiva OC-21/14 de 19 de agosto de 2014. 